\title{
Analysis of microbiota associated with dental implant overdenture attachment
}

\section{Abstract}

This study was to investigate the distribution of pathogenic microorganisms around the attachments and implants of implant overdentures in edentulous patients and to also analyze the correlation between overdenture-related bacteria and clinical indices. Periodontal pathogenic bacteria were detected in most patients, and amounts of bacteria as much as those found in the peri-implant sulcus and around intra-oral attachments were also detected in the attachments of denture bases. These results imply that the increase in the number of periodontal pathogenic bacteria is effected by the periodontal pocket probing depths and the modified sulcular bleeding indices in patients using implant overdentures.

\section{Background and Aim}

Implant overdenture plays an important role in treatment option for edentulous patients. Failures on implant restoration by bacteria induced inflammation were frequently reported. Therefore, oral pathogens related with peri-implantitis are actively studied. However, these results are imited to peri-implantitis of fixed restorations. The aim of this study is to investigate and compare the distribution of microbiota around attachment of implant overdenture and implant, and support the information for the treatment protocol for patients who need implant overdenture.

\section{Methods and Materials}

The study was performed targeting the patients with implant overdenture. Samples were collected from the oral surface of the abutment (Abutment) the bottom of implant sulcus with the greatest probing depth (Sulcus), attachment housing in denture (Denture) with microbrush. Each patient was evaluated by measuring probing depth, modified sulcus bleeding index. The bacterial DNA was extracted from samples by bacterial DNA extraction kit. Quantification of Filifactor alocis, Fusobacterium nucleatum, Streptococcus sanguinis, Prevotella intermedia, Porphyromonas endodontalis, Porphyromonas gingivalis, Tannerella forsythia and Treponema denticola in samples was analyzed by real-time polymerase chain reaction using the extracted DNA. The relationships between quantification of the bacteria and sampling area were investigated with Friedman test. Correlations between quantification of the bacteria and probing depth were analyzed with Spearman rank correlation coefficient. The relationships between DNA quantification of bacteria and modified probing index were investigated with Jonckheere-Terpstra test.

Table I. The primer sequences for real-time PCR

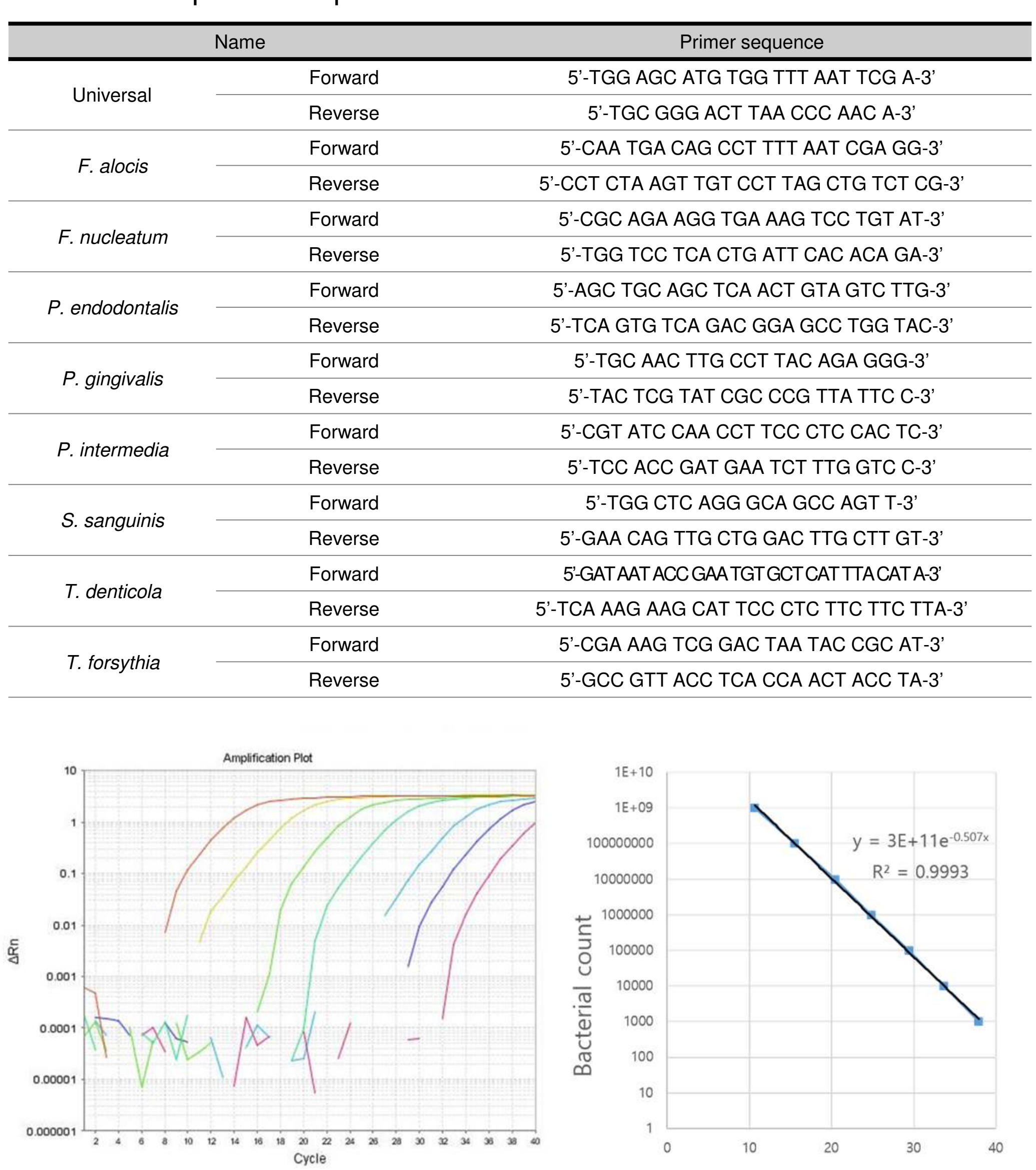

Figure 1. A standard curve was produced using the already-known concentration figure of DNA per number of bacteria and the threshold value.

\section{Results}

Table $\amalg$. The primer sequences for real-time PCR

\begin{tabular}{|c|c|c|c|c|}
\hline \multirow{2}{*}{ Bacteria } & \multicolumn{4}{|c|}{ Patient count (\%) } \\
\hline & Abutment & Sulcus & Denture & Total \\
\hline F. alocis & $20(100)$ & $20(100)$ & $20(100)$ & $60(100)$ \\
\hline F. nucleatum & $20(100)$ & $20(100)$ & $20(100)$ & $60(100)$ \\
\hline P. endodontalis & $12(60)$ & $13(65)$ & $12(60)$ & $37(62)$ \\
\hline P. gingivalis & $4(20)$ & $5(25)$ & $7(35)$ & $16(27)$ \\
\hline P. intermedia & I4 (70) & $14(70)$ & $14(70)$ & $42(70)$ \\
\hline S. sanguinis & $19(95)$ & $19(95)$ & $19(95)$ & $57(95)$ \\
\hline T. denticola & $4(20)$ & $8(40)$ & $7(35)$ & $19(32)$ \\
\hline T. forsythia & $14(70)$ & $14(70)$ & $15(75)$ & $43(72)$ \\
\hline
\end{tabular}

Table III. Correlation between bacterial count and probing depth.

\begin{tabular}{cccc}
\hline Bacteria & Abutment & Sulcus & Denture \\
\hline F. alocis & $0.004^{*}$ & $0.003^{*}$ & $0.013^{*}$ \\
\hline F. nucleatum & $0.044^{*}$ & $0.048^{*}$ & $0.016^{*}$ \\
\hline$P$. endodontalis & $0.001^{*}$ & $0.001^{*}$ & $0.002^{*}$ \\
\hline P. gingivalis & 0.209 & 0.244 & 0.469 \\
\hline P. intermedia & 0.082 & $0.046^{*}$ & 0.14 \\
\hline S. sanguninis & 0.848 & 0.521 & 0.625 \\
\hline T. denticola & $0.041^{*}$ & $0.007^{*}$ & $0.02^{*}$ \\
\hline T. forsythis & $0.031^{*}$ & $0.007^{*}$ & 0.237 \\
\hline
\end{tabular}

Spearman's rank correlation coefficient test, ${ }_{p}<0.05$

Table IV. Correlation between bacterial count and modified bleeding index.

\begin{tabular}{cccc}
\hline Bacteria & Abutment & Sulcus & Denture \\
\hline F. alocis & 0.109 & 0.093 & $0.023^{*}$ \\
\hline F. nucleatum & 0.391 & 0.351 & $0.015^{*}$ \\
\hline P. endodontalis & 0.126 & $0.048^{*}$ & 0.057 \\
\hline P. gingivalis & 0.351 & 0.093 & 0.167 \\
\hline P. intermedia & 0.145 & 0.314 & 0.168 \\
\hline S. sanguninis & 0.794 & 0.911 & 0.911 \\
\hline T. denticola & 0.328 & 0.106 & 0.232 \\
\hline T. forsythia & 0.576 & 0.434 & 0.97 \\
\hline
\end{tabular}

Jonckhere-Terpstra test, $\left.{ }_{p}<005\right)$

S. sanguinis, F. alocis, F. nucleatum T. forsythia were detected in most of subject. The detection ratio of $F$ alocis, $F$. nucleatum were $100 \%$. When comparing oral surface of the attachment, the bottom of implant sulcus with the greatest probing depth and attachment housing in denture, no relationships observed between sampling site and the bacteria quantification.

A significant positive correlation between probing depth and the bacterial quantification of $F$. alocis, $F$. nucleatum, $P$. endodontalis, $T$. forsythia, $T$. denticola showed. Also a significant positive correlation between modified bleeding index and bacterial DNA quantification of $F$. alocis in Denture group, F. nucleatum in Denture group, and $P$. endodontalis in Implant group exhibited. These results indicate clinical indices related with periodontopathogens.

\section{Conclusions}

Quantification of main periodontopathogens as red complex bacteria had increased according to increasing clinical indices. These results indicates oral environment of patient with implant overdenture and attachment housing in denture has possibility of colonization of periodontopathogens. Therefore, it is need to know that implant overdenture may have biological complications similar to peri-implantitis and provide preventive treatment and hygiene education to overdenture patients.

\section{References}

Furst MM, Salvi GE, and Lang NP (2007) Persson GR. Bacterial colonization immediately after installation on oral titanium implants. Clin Oral Implants Res, 18:501-8.

Socransky SS, Haffajee AD, Cugini MA, Smith C, Kent RL Jr. (1998) Microbial complexes in subgingival plaque. J Clin Periodontol, 25:134-44.

Cortelli SC, Cortelli JR, Romeiro RL, Costa FO, Aquino DR, and Orzechowski PR. (2013) Frequency of periodontal pathogens in equivalent peri-implant and periodontal clinical statuses. Arch Oral Biol, 58(1):67-74.

At-Radha AS, Pal A, Pettemerides AP and Jenkinson HF. (2012) Molecular analysis of microbiota associated with peri-implant diseases. J Dent, 40(11):989-98.

Sordyl CM, Simons AM and Molinari JA. (1995) The microbial flora associated with stable endosseous implants. J Oral Implantol. 21(1):19-22. 